Archivum, LXVII, 2017, pp. 117-156

\title{
El episodio de la cueva de Montesinos: hacia la cordura
}

Recibido: 23/11/2017

Aceptado: 18/12/2017

\section{RESUMEN:}

La aventura de la cueva de Montesinos (capitulos XXII y XXIII de la segunda parte de El Quijote y alusiones en otros capítulos) relata la anécdota de la bajada del caballero a la cueva, donde permanece, según sus acompañantes, media hora, y según él, tres días, en los que vive una realidad paralela de romances, encantamientos y fantasías. El análisis semiótico relaciona este episodio con otros: el de Sansón Carrasco, el del Caballero del Verde Gabán, el encantamiento de Dulcinea, y muestra que, bajo anécdotas diversas, todos plantean temas sobre la posibilidad del conocimiento: la realidad, los sentidos, la palabra, la verdad, el engaño, etc. Las discordancias del tiempo dentro y fuera de la cueva remueven la consciencia de don Quijote e inician su vuelta a la cordura que desenlazará la novela cervantina.

PALABRAS CLAVE: el Quijote, cueva de Montesinos, conocimiento, semiótica, cordura.

The episode of the cave of Montesinos: towards sanity

\section{ABSTRACT:}

The adventure of the cave of Montesinos (chapters XXII and XXIII of the second part of don Quixote, and allusions in other chapters) narrates the anecdote of the descent of the knight to the cave, where he remains, according to his companions, half an hour, and according to himself, three days, in which he lives a parallel reality of romance, enchantment and fantasy. A semiotic analysis relates this episode to others: the one 
with Sansón Carrasco, the one with the knight of the Green Cloak, the enchantment of Dulcinea, and shows that, through diverse anecdotes, all of them raise issues about the possibility of knowledge: reality, the senses, language, truth, deception, etc. The unconformities of time inside and outside the cave shake don Quixote's consciousness and initiate his return to sanity that will bring Cervantes' novel to its denouement.

KEYWORDS: don Quixote, cave of Montesinos, knowledge, semiotics, sanity.

La visita a la cueva de Montesinos es una de las aventuras más relevantes de la segunda parte de El Quijote, tanto por su función en la trama, como por su forma de manifestación en el discurso. Se anuncia en el capítulo XVIII, y se desarrolla con variada extensión en varios de los siguientes, mediante acciones y comentarios.

Después de cuatro días de estancia y agasajo en casa de don Diego de Miranda, don Quijote quiere marcharse, porque debe cumplir con su oficio y recorrer los caminos en busca de entuertos que corregir y daños que remediar; naturalmente Sancho, que estaba muy ricamente atendido, no tiene prisa por irse de una casa tan bien abastecida, pero prevalece la voluntad del amo y salen al camino.

El caballero expresa su intención "de entrar en la cueva de Montesinos, de quien tantas y tan admirables cosas en aquellos contornos se contaban" (176), pero el relato no pasa a cumplir este propósito de forma inmediata, sino que lo dilata, interponiendo otra aventura, la de las bodas de Camacho. La despedida de las bodas de Camacho repite los mismos pasos que la despedida de la casa de don Diego: después de tres días de regalo, don Quijote, con el pesar de Sancho, quiere volver al camino, y pide una guía que lo conduzca seguro y avisado a la cueva de Montesinos, "porque tenía gran deseo de entrar en ella y ver a ojos vistas si eran verdaderas las maravillas que de ella se decían por todos aquellos contornos"(174). Podemos preguntarnos si la reiteración de los términos de la despedida, idéntica en sus pasos y alusiones es un recurso de intensificación para dar relieve al episodio de la cueva. 
El anuncio y la preparación de la anécdota quedan subrayados en las despedidas de la casa de don Diego y de las bodas de Camacho, que reitera las intenciones de ir a la cueva e inicia los preparativos. El episodio se anuncia y se subraya, de forma idéntica, en las dos ocasiones: don Quijote había planeado comprobar lo que decían, aunque se interpusieran otras aventuras $\mathrm{y}$, aunque Sancho prefiriera quedarse donde estaban, prevalecen los planes de su amo, como es lógico. La trama avanza, y la visita a la cueva pasa a un primer plano del discurso, como un relato vivido, no como un plan que se propone o como un recuerdo que se cuenta. El esquema argumental del episodio es muy sencillo: don Quijote, con la ayuda de sus amigos, baja al interior de la famosa cueva (capítulos XXI y XXII); al salir cuenta lo que ha visto, y en capítulos siguientes diversos personajes comentan lo que ha contado y plantean dudas sobre su verosimilitud y su certeza; el motivo es objeto de discusiones y comentarios directos entre el primo humanista, Sancho y don Quijote y se va desvaneciendo en opiniones y reflexiones en otros dos capítulos hasta el episodio de la venta, con Maese Pedro y el mono sabio. Luego, ya iniciado el cambio estructural del relato y anunciado su desenlace, el tema de la cueva desaparece del discurso; ha servido de filtro de actitudes de los sujetos sobre la confianza de unos en otros, sobre engaños posibles, oposición y contraste de verdad o mentira, perplejidad en todos y otras actitudes de desconfianza, rechazo, burla, humor, etc. En planteamientos sucesivos y desde ángulos diversos el tema de la cueva de Montesinos señala relaciones de los personajes, mantiene gran relieve estructural en la trama y adquiere una gran densidad semántica, que trataremos por partes, en sí mismo y por comparación con otros episodios.

Es una aventura original, muy cuidada en su manifestación discursiva y minuciosa en los detalles; su relieve en la trama, según creemos, proviene de las relaciones que establece con otros episodios, no por la anécdota, sino a propósito de problemas sobre el conocimiento y la certeza, la experiencia y los sentidos, la fantasía, la palabra, el significado y su sentido en el conjunto se- 
miótico en la novela. Su interés no se limita a la anécdota y a los personajes, no es una simple curiosidad, ni tampoco el contraste entre el relato fantástico que dice haber vivido don Quijote, con episodios del romancero de Durandarte, Belerma y Montesinos, ni al encuentro con la encantada Dulcinea, frente a la realidad de afuera de la cueva donde quedan Sancho y el primo humanista. Su relieve procede de la historia medular en la novela: la locura de don Quijote y la recuperación de la razón en el desenlace, y se plantea justo en el contraste de la cronología de dos espacios, concretamente en la oposición entre el tiempo fuera de la cueva, del que dan fe Sancho y el primo, y el tiempo dentro, tal como don Quijote dice haberlo vivido.

El tiempo que don Quijote dice que vivió en la cueva (tres días) no corresponde con el que vivieron fuera los otros personajes (una hora). Y de esta discordancia temporal derivan temas sorprendentes, que ponen al episodio en relación con otros que cuestionan también las posibilidades semióticas del marco espacio-temporal del relato, la verdad del conocimiento, el valor de la palabra, la interferencia del mundo real con el fantástico y, sobre todo, lo hacen encajar en una nueva orientación que inicia el camino hacia el desenlace de la novela, con la recuperación de la cordura del caballero. $Y$, por otra parte, se vincula de forma directa al tema del encantamiento de Dulcinea, porque don Quijote asegura haberla visto en el interior de la cueva, brincando, con sus damas y vestidas como se las había mostrado Sancho a la salida del Toboso, cuando las había encantado por su cuenta y riesgo. Hay además relaciones textuales y argumentales con otros episodios, que iremos viendo en los aspectos más destacados, y cuyo tema común es el problema de la realidad y del conocimiento, sus elementos y el proceso que sigue para alcanzar la certeza.

El caballero acaba el relato de lo que vivió dentro de la cueva y el primo humanista, desde su sentido crítico, apunta: “yo no sé [...] cómo vuestra merced en tan poco espacio de tiempo como ha que está allá abajo, ha visto tantas cosas y hablado y respon- 
dido tanto" (219). Según el tiempo exterior ha estado abajo poco más de una hora, $\mathrm{y}$, sin embargo, don Quijote afirma que "allá me anocheció y amaneció y tornó a anochecer y amanecer tres veces, de modo que tres días he estado en aquellas partes" (219). Hay, pues, gran diferencia entre el tiempo de afuera y de adentro: ¿cuál es el verdadero? Y es importante, porque en relación con el tiempo, se articulan muchos aspectos, entre ellos el de la veracidad, las intenciones y propósitos de engaño, el honor del sujeto del testimonio, etc. don Quijote dice verdad o miente: el honor está en juego, y el caso no se vincula sólo a la fantasía del romancero, se alarga al presente de las relaciones con Dulcinea, con Sancho, con el primo, con la secuencia de funciones en la línea que va desde la razón a la locura en el comienzo de la novela y el regreso a la cordura, en el desenlace de la historia. La trama de El Quijote se diseña desde la pérdida de la razón del caballero, debida a la lectura de las novelas de caballería, hasta la recuperación de la razón cuando se apea del mundo de la fantasía y se le impone la realidad, y este camino de retorno a la razón se inicia precisamente por el desconcierto que don Quijote no puede superar al poner en evidencia que una hora fuera de la cueva sean tres horas en su interior: la seguridad que las coordenadas espacio-temporales proporcionan al conocimiento es incompatible con lo que don Quijote cuenta que vivió.

El relato y los comentarios sobre la aventura de la cueva de Montesinos están presentados en un discurso con calma, muy modalizados, es decir, orientados en su conjunto a destacar las discordancias de los tiempos, como un tema de reflexión y no como un motivo de enfrentamiento; si el lector avanza en el texto con atención, puede ver que todo se articula hacia el mismo problema: explicar lo que parece inexplicable. Hay una ironía que alerta sobre la objetividad de lo ocurrido a don Quijote y suscita el interés sobre los sujetos y sus circunstancias en la percepción de los hechos. Sancho, ducho en sorpresas y explicaciones en el mundo de la caballería y de magos y encantadores que persiguen a su amo, y creador de algunas vías en la palabra que pue- 
den distorsionar la percepción de la realidad, ofrece de inmediato una interpretación genérica: todo puede ser cosa de esos encantadores, celosos de la fama y envidiosos del valor y arrojo de los caballeros.

Pero el tema, que otras veces se cerraría como un episodio de encantamiento a favor de uno de los personajes que intervienen, deriva hacia consideraciones gnoseológicas, de aceptación o de rechazo del discurso y de sus procesos previos, de percepción por parte de los sentidos y de conocimiento por parte del discurso: ¿lo que cuenta don Quijote es verdad o es mentira?, ¿don Quijote está engañado, lo ha soñado de verdad o ha tejido una historia para engañar?

Sancho aviva el problema al decirle a su amo que "de todo lo que ha dicho no creo cosa alguna" (219). Y es que Sancho no puede creer en un mundo donde está Dulcinea encantada, porque sabe muy bien quién es el autor de su encantamiento y quién envió a su señora a ese mundo, sin participación de más encantadores que él mismo. Todos están perplejos: hay sorpresa suficiente para todos, incluidos algunos no presentes, que se incorporarán en capítulos posteriores.

Sin duda el efecto más destacado que deriva de la perplejidad de don Quijote (y suponiendo su honestidad epistemológica, es decir, que no ha preparado él mismo la mentira), es el comienzo de un cambio en su percepción del mundo caballeresco que él vivía con tanta seguridad en su fantasía, y que le dejaba ser él mismo y los doce pares de Francia juntos, si hacía falta. Hasta ahora tomaba por verdad indiscutible todo lo que imaginaba y nunca se planteó diferencias entre la realidad y el mundo de la caballería cuyos límites y cuya certeza quedaban fuera de duda y sólo se alteraban por encantamientos; ahora no puede explicar desde un canon de verdad objetiva y de lógica pragmática que el tiempo de lo vivido dentro de la cueva sea diferente del transcurrido fuera.

El testimonio, en el supuesto de que sea bienintencionado y él lo considere verdadero, se queda solo frente a lo que dicen los 
demás, y esto le hace pensar, reflexionar atentamente sobre sus extremos, volver una y otra vez sobre lo mismo: ¿dónde está la verdad?, ¿cuál de los tiempos y, por tanto, cuál de los relatos es verdadero?, pues los dos a la vez no pueden serlo. Las reflexiones de don Quijote nacen sobre la discordancia realidad - fantasía y sobre los tiempos y espacios (fuera - dentro) que les sirven de marco, uno real y el otro fantástico, pues los dos reales no pueden serlo. Desde esta perspectiva, el problema planteado no tiene solución. Esto en el supuesto de la buena fe del héroe.

Pero el problema se complica con una nueva consideración: la posibilidad que se insinúa de que don Quijote mienta. Las reflexiones sobre todo esto socavan sus principios, inquietan su ánimo, y encaminan a don Quijote hacia la recuperación de la prosaica lógica y, en último término, de la cordura, donde la amarga realidad sigue unas leyes diferentes a las que rigen en la libertad absoluta de la fantasía. El mundo de la experiencia no es el mundo de la fantasía, y éste que siempre prevaleció, empieza a quebrarse entre las manos y ante los ojos de los personajes. Sería mejor abordar el tema desde enfoques nuevos.

Suponiendo que don Quijote no mienta, habrá que interpretar que inicia su vuelta a la realidad porque no puede soportar las discordancias temporales, porque son demasiado fuertes. $\mathrm{O}$, por el contrario, el caballero ofrece conscientemente desde el principio un engaño, es decir, ¿estaría su ánimo con capacidad suficiente para seguir la lógica de la fantasía y la lógica de la realidad y hace ver que se mueve con soltura entre las dos?

Y aquí está la nueva lectura del episodio de la cueva de Montesinos. Si se analiza desde una perspectiva gnoseológica aparecen conexiones con otros episodios, no es un motivo aislado, en la oposición experiencia - fantasía, con sus alternativas verdad - mentira: ¿es cierto que don Quijote, según él dice, y no hay otras fuentes de información, vivió tres días en la cueva, de la que sale dormido, y no inventó lo que cuenta?, ¿es cierto lo que dice el primo sobre el tiempo fuera de la Cueva, que es poco más de 
una hora, según conviene Sancho, o quizá mienten para poner a prueba al caballero? No pueden admitirse las dos cosas, pueden ser mentira los dos relatos, pero no pueden ser verdad las dos. Y si no es verdad el tiempo, ¿puede ser verdadera la experiencia vivida en él? Las historias y los personajes que don Quijote vio y con los que habló ¿son efecto de su imaginación, es decir, aparecen de forma espontánea y él así lo cree, o él los ha traído a su memoria con el fin de sorprender a Sancho y al primo? ¿Debe don Quijote renunciar a su seguridad y admitir que lo que cree haber vivido no es real, sino que pertenece al mundo de la fantasía y de los sueños? ¿Actúa don Quijote con engaño o de forma ingenua?

El lector puede tomar por cierto el relato de don Quijote o plantearse las dudas de sus amigos, al confrontarlo en sus referencias cronológicas. El caballero no está seguro de sus vivencias dentro de la cueva, que enmarca en tres días, al ver que se queda sólo con su testimonio, y se producen continuos interrogantes, surge la posibilidad de relaciones con otros episodios, reflexiones sobre nuevos aspectos: todo subraya el interés de la aventura en la trama. Desde luego no estamos ante un episodio menor cuya función sea acumulativa o copulativa entre otros, de entretenimiento y espera, de eco para subrayar una relación, etc. Se trata de un episodio sustantivo, que forma núcleo con otros para analizar temas sobre el conocimiento, sus elementos, sus partes, el proceso que sigue el sujeto para lograrlo, etc... Y, como ocurre casi siempre, el texto literario plantea cuestiones complejas que no soluciona, pero las sitúa como centro de interés en la cultura $\mathrm{y}$ en la historia humana.

Y cuando los personajes y el lector llegan a una situación de perplejidad, el narrador se ve obligado a intervenir para explicar hasta donde puede, que no es todo el proceso o sus intenciones, y la perplejidad se mantiene. El cap. XXIV subraya que el discurso de don Quijote desconcierta y no puede ser admitido como verdadero, porque hasta ahora sus aventuras siempre habían sido contingibles y verisimiles, pero la de la cueva de Montesinos queda 
muy fuera de los términos de la razón y descoloca al lector completamente, no le ofrece un camino de salida indudable.

En esta situación extrema, se insinúa la alternativa que se insinuaba y se va abriendo camino: puede que don Quijote mienta, aunque sería difícil admitirlo, siendo tan buen caballero como es; una cosa es que se equivoque por caminos que le sugiere su fantasía y su locura, o incluso que acuda a los encantadores y magos, cuando no alcanza a explicar algo, y otra actitud muy distante es que él mismo tenga dudas y quiera epatar y contar historias sabiendo que son patrañas caballerescas o romanceras. Y más sorprendente aún es la actitud del caballero ante el encantamiento de Dulcinea: ¿cree lo que Sancho le ha dicho y lo asimila a su historia fantástica, o juega al absurdo con ese dato para dar jaque a su escudero? Puede ser que las dudas sobre ese mundo de caballerías donde antes se sentía tan seguro, empiecen a desasosegarlo y lo empuje a la verificación, que hasta ahora no era necesaria, o bien que lo haga desembocar en el absurdo, que no exige lógica. La ambigüedad entre las dos interpretaciones está en el centro de la trama, en este episodio y le da peso en la estructura narrativa del relato a cuyo desenlace se vincula; por eso el discurso dedica mucho tiempo al tema y destaca muchos y muy sutiles matices. El quid de la cuestión está en la actitud de don Quijote: ¿es el engañado o es el engañador?, ¿se inicia aquí la vía hacia su cordura, porque le resulta excesivo e insoportable el contraste entre su imaginación y la realidad, tal como se centra en la coordenada cronológica de la imaginación en la cueva o la realidad fuera de ella, o don Quijote aprovecha la circunstancia para engañar a sus amigos y quizá para engañarse él mismo y continuar su historia con cierta verosimilitud?

El problema planteado es arduo y el narrador acude como extremo a la intervención textual de Cide Hamete Benengeli, autor de la novela y máxima autoridad del relato, incluso frente al narrador-traductor, pero tampoco resuelve el embrollo, a pesar de tener las riendas de la historia, como primer autor. La aventura 
es tan excesiva que parece apócrifa, y el autor decide incluirla sin entrar en si es falsa o verdadera, meollo de su valor en la estructura de la trama, pero lanza un cable muy inquietante, que nunca confirmará la verdad o el engaño de la historia: adelanta que don Quijote en la hora de su muerte "se retrató della, y dijo que él la había inventado" (223), porque sencillamente encaja bien, pero al final de la novela no llega a aclararlo, ni siquiera a plantearlo.

El lector que espere una lógica narrativa, queda desconcertado: en la presentación del problema asoma la duda sobre su verdad o mentira, y no se aclara por testimonios inmediatos, sino que remite al desenlace de la novela cuando, según dice, don Quijote se retractará, cosa que no ocurre: ¿es un despiste o está premeditado? El capítulo XXIV afirma rotundamente que es impensable que don Quijote mienta y deja en el aire el testimonio del primer autor, Cide Hamete Benengeli. La lógica estructural es diferente en los autores y en los personajes, de modo que el lector no puede estar seguro y se decidirá por el sentido que personalmente más le convenza, ya que todos los testimonios textuales se le presentan en forma ambigua. La remisión al final de la historia y a la muerte de don Quijote con la aclaración decisiva sobre la mentira del episodio, si en efecto fue urdido intencionalmente por su relator, señala el eje estructural de la recuperación de la cordura de don Quijote.

Otra alusión a la cueva de Montesinos se encuentra en el cap. XXV (238) cuando Sancho sugiere a don Quijote que pregunte al mono de Maese Pedro si es verdad lo que le pasó, ya que él cree "que todo fue embeleco y mentira, o por lo menos cosas soñadas." don Quijote se aviene a preguntar a fin de que no le quede "un no sé qué de escrúpulo." La contestación del mono mantiene la ambigüedad y remite la contestación al viernes siguiente ya que parte de las cosas "que vuestra merced vio, o pasó, en la dicha cueva son falsas, y parte verisímiles" (238). Al mono se le había acabado la virtud de adivinar y hasta el viernes siguiente no estará de nuevo inspirado en su oficio, de modo que no se resuelve el problema. 
De todos modos, hay otra lectura muy interesante: la posibilidad de relacionarlo con varios episodios que ofrecen reflexiones sobre la realidad, la experiencia, la comunicación, la manipulación de la palabra, el conocimiento y la certeza. El motivo de la cueva de Montesinos no es el único que plantea problemas de este tipo: se encuentran varios que responden a un análisis desde una perspectiva gnoseológica y descubren nuevos sentidos en un cuadro general sobre los procesos del conocimiento.

$Y$ en este enfoque, señalamos que la aventura de la visita a la cueva de Montesinos forma serie con el episodio de Sansón Carrasco y Tomé Cecial, que plantea la oposición realidad - palabra (lo que es / lo que se dice), entra en relación con la larga historia del Caballero del Verde Gabán, don Diego de Miranda, centrada en oposición realidad - conocimiento (experiencia / saber), que da lugar a opiniones, impresiones, valoraciones, etc., al comparar la conducta del caballero y sus discursos, que tiene desconcertados a don Diego y a su hijo don Lorenzo. $Y$ de forma inmediatamente textualizada en el mismo episodio, la aventura de la cueva de Montesinos también entra en relación con el tema transversal del encantamiento de Dulcinea que Sancho, vista la confusión y rentabilidad de sus encantamientos y transformaciones, había urdido y que encaja en la alternativa realidad - palabra. Y es curioso que don Quijote asegura haber visto a Dulcinea y a sus dos damas vestidas de la misma manera en que Sancho se las había presentado a la salida del Toboso: ¿quiso don Quijote utilizar la mentira de Sancho para urdir la suya en Montesinos y hacer ver a su escudero que tampoco él cree en su embeleco? Estaríamos ante un juego muy retorcido, sobre el regador regado, o sobre la reducción al absurdo de los argumentos del escudero, que don Quijote aparentó creer, porque era su propio método para salir de embrollos.

Cada uno de estos episodios tiene su propio argumentario en los problemas que suscita el proceso del conocimiento: a) el episodio de Sansón se centra en el papel de los sentidos, cuya información se niega; b) la historia de don Diego se orienta hacia 
el espinoso caso de la interpretación condicionada por los prejuicios que impiden actuar rectamente al entendimiento en sus deducciones; c) las coordenadas cronotópicas, que sirven de marco a la verdad, son un simple accidente sin relevancia respecto a la verdad y al saber y cada sujeto las interpreta a su modo, y d) la estructura lógica de la verdad o la mentira en relación con la experiencia y con las intenciones del sujeto, puede cambiar: don Quijote miente, o simplemente está abducido por lo que inventó o soñó, o por lo que le dijo su escudero respecto al estado de Dulcinea, pero quizá sería demasiado pensar que no cree nada de lo que tramó Sancho. Las dudas sobre la posición de cada uno de los personajes y de sus posibles relaciones se suceden en cada interpretación y mantienen una ambigüedad difícil de disipar.

Todos los episodios relacionados están narrados en un plano subjetivo por uno de los personajes, todos oscilan entre visiones, opiniones e interpretaciones, en los que intervienen la locura (don Quijote), el interés (Sancho), los prejuicios (don Diego). Los personajes experimentan, creen, inventan, traducen a palabras, proponen conocimientos sobre objetos, individuos, personajes y hechos que confunden al lector, pues él no los ve de la misma manera, y porque entran en contradicciones internas desde interpretaciones que la lógica de cada personaje rechaza: la confusión está servida y el análisis del conocimiento desemboca en cada individuo en la duda, cuando lo piensa, y en la perplejidad cuando lo afronta e intenta encajarlo en el relato.

En todos estos episodios se analiza de algún modo cómo la realidad, que captan los sentidos, constituye el objeto del conocimiento y cómo la palabra, medio de expresión para dar forma semiótica que pueda ser captada por otros sujetos y transmitir así el conocimiento que adquiere cada personaje, no es una forma inocua, pues puede ser manipulada para confundir, con intención o sin ella, al emisor o al receptor de cualquier proceso de expresión, de comunicación, de significación, de interpretación y de transducción; quizá también la palabra muestra su insuficiencia a la hora de objetivar el conocimiento, lo que se quiere o lo 
que se piensa, pues ni la intención del narrador, ni los contenidos interiores son verificables objetivamente.

Don Diego de Miranda, ante los datos que le ofrece la realidad: el comportamiento y la palabra de don Quijote, y comparándolos con los que habitualmente se toman como razonables, se desconcierta, no sabe si admirarlo por la sabiduría de sus palabras, o considerarlo un tonto por sus afirmaciones sobre la caballería andante y por sus actos descabellados; el trato de varios días de convivencia no alcanza a aclarar el dilema, ni a disipar las dudas.

La misma indecisión y perplejidad sienten don Quijote y Sancho ante dos personajes, que tienen la apariencia de Sansón Carrasco y Tomé Cecial, bien conocidos por ellos, pero que se presentan y dicen ser el Caballero del Bosque y su escudero. Frente a don Diego de Miranda que trabaja con datos que él mismo observa y se expresa con sus propias palabras, Sansón pretende cambiar el conocimiento presentándose con sus datos verdaderos cambiados intencionalmente en otros falsos.

La tosca labradora que Sancho asegura que es Dulcinea encantada, produce perplejidad en don Quijote, que no puede admitir ni convencerse que su dama tenga tal apariencia: es excesiva la distancia entre la realidad imaginada y la realidad empírica, por muy encantada que esté Dulcinea. Una cosa es la palabra y otra su referente, y si estos términos están tan distanciados, ¿quién puede explicar una conciliación o qué apoyos puede tener el conocimiento para alcanzar la certeza? Y, sin embargo, don Quijote entra en el juego del encanto de Dulcinea, cosa que desconcierta a Sancho: ¿a qué juega su señor?

Más allá de la anécdota, éste es el planteamiento y los cruces del episodio de la cueva de Montesinos: don Quijote no puede entender que sus vivencias de tres días dentro de la cueva se correspondan con un tiempo empírico de apenas una hora, fuera de la cueva, según lo viven Sancho y el primo humanista. La certeza no parece posible: objetos, experiencias y palabras no 
son elementos seguros para el conocimiento, son el objeto del conocimiento, si el tiempo y el espacio actúan como marco y si los sujetos que los utilizan no los manipulan contra la lógica. Si la certeza no se puede apoyar en la experiencia y el saber no admite verificación $y$, por otra parte, no se alude para nada al principio de autoridad y no hay maestro que descarte dudas, nadie tiene la última palabra en este juego de discordancias. $Y$ don Quijote entra en el oscuro ámbito de la duda, en el que seguirá hasta el desenlace de sus aventuras, cuando al final del relato recupere la razón. Y esto suponiendo que no hay mentira en sus palabras, como se descarta y se insinúa, sin llegar a negarlo de forma total.

Los cuatro episodios señalados podrían constituir la secuencia de funciones de la trama de un relato, con anécdotas diversas, en relaciones causales, de contraposición o de otro tipo que mantengan los mismos personajes, pero encuentran también unidad en un análisis gnoseológico: todos orientan el camino hacia la cordura de don Quijote, pues suscitan dudas que mueven a buscar certezas.

La voluntad del sujeto para verificar la verdad y el engaño, su interés o desinterés por el conocimiento, la posibilidad de convertir el saber en signos verbales u otro tipo de unidades semióticas que le den forma objetivada para poder transmitirlo, y la necesidad de demostración y de verificación, son los temas que están bajo la anécdota de estos y otros episodios. Todas las alternativas de la relación entre realidad, conocimiento y expresión semiótica, se plantean como dudosas, en cuanto son manipulables y dependen del sujeto, de modo que obligan a meditar sobre su verosimilitud, a revisarlas y a abordar su comprensión desde la lógica, planteándolas en forma problemática, pues no son causales ni necesarias en las secuencias que las insertan.

Podríamos añadir a los cuatro episodios citados, otros que ofrecen también variantes de problemas gnoseológicos y plantean dudas en las relaciones estáticas o progresivas de sus ele- 
mentos, pero vamos a centrarnos en la aventura de la cueva de Montesinos y los más inmediatos que hemos señalado, y en la discordancia cronotópica que cuartea las bases de la credibilidad y generan dudas sobre la verdad del conocimiento en las vivencias que don Quijote presenta como experiencias vividas dentro de la cueva.

Cervantes presenta muchos personajes que quieren conocer y quieren ser conocidos, y pone ejemplos con motivos y anécdotas que indirectamente plantean temas, de forma pragmática o teórica, sobre los elementos del conocimiento y su proceso, que puede considerarse como cierto, o generar dudas en todas las relaciones: la del sujeto con la realidad, la del sujeto con la palabra, la verdad con la palabra, la certeza con el engaño, la relación de un sujeto con otro, de autoridad, de ejemplaridad, de conocimiento total o relativo, etc. La teoría también pone en duda el valor de los sentidos para captar datos y relaciones o para confirmar conocimientos, la capacidad de la palabra para dar forma a las ideas, a los hechos, a las fantasías, etc., para describir o caracterizar a los sujetos, para realizar procesos de expresión, de significación, de comunicación, para manifestar la experiencia que cada sujeto adquiere, el interés general o particular del proceso gnoseológico, etc. Los temas se multiplican en hechos y relaciones y se abren a la realidad, al sujeto, a la duda, a la certeza, a la palabra, etc., a medida que el análisis avanza en el descubrimiento y manifestación de relaciones. Los elementos que intervienen en el conocimiento se textualizan en una amplia casuística de situaciones, funciones y conocimientos en los episodios de El Quijote, y se erigen en un marco de interpretación general que conecta gran número de motivos a veces muy diferentes en su anécdota, en su extensión, y con muy diferentes sujetos. Todo indica que la estructura de la novela no es una serie seguida de anécdotas, más o menos divertidas, sino que traspasa posibles relaciones del relato en las aventuras, en una cadena de relaciones filosóficas, semióticas, lingüísticas y, en general, humanísticas, que el lector sigue con interés. 
Sobre historias diversas, cuyo valor y cuyas diferencias se han destacado por la originalidad de sus funciones o por la singularidad de sus personajes, y también por la relación causal en que se presentan, podemos señalar planteamientos gnoseológicos, que establecen fuertes relaciones internas entre las funciones y sus actantes, en varios episodios. Todas vienen a plantear interrogantes sobre la posibilidad de identificar la realidad y alcanzar conocimientos sobre ella, sobre la posibilidad de conocer a otros hombres, sobre la posibilidad de prescindir de las coordenadas de espacio y tiempo, sobre la certeza del saber, sobre la necesidad de dar forma objetiva que fije semióticamente el conocimiento, en signos codificados, para poder transmitirlo...

Si el análisis de los episodios conexionados se detiene en estos aspectos irá descubriendo la dimensión de los planteamientos cervantinos que en principio parecen circunstanciales, si quedan reducidos a las anécdotas de la trama, pero que en realidad son un muestrario de posibilidades en las relaciones del conocimiento de la realidad y de su expresión verbal, verdadera o falsa, de hablantes con buenas o malas intenciones, con ingenuidad o con malevolencia: Sansón miente por un objetivo bueno; don Diego, en su visión de pequeño burgués, es incapaz de tomar partido y opinar con soltura, y se siente perplejo por la imposibilidad de llegar a un conocimiento cierto; no miente pero no alcanza certeza, su estado es de duda; Sancho miente por interés en el encantamiento de Dulcinea para salir del apuro en que se ha metido; don Quijote en principio no miente y tiene seguridad, pero empieza a dudar precisamente cuando confronta la fantasía vivida en la cueva con la realidad de los otros sujetos, y al final el autor remueve todo el argumento cuando se refiere al desenlace de la novela y a un hecho que luego no aparece: anuncia que el personaje se retractará de lo contado y admite que fue una mentira graciosa, pero no es así, en el texto no aparece el tal retracto, y más que graciosa, la visita a la cueva es estructural en la historia.

El conjunto de estos episodios, de sus personajes, de sus actitudes, de los conocimientos que alcanzan, etc., es toda una teo- 
rización sobre las posibilidades de conocer, de comunicar y de engañar que tiene el hombre, su palabra y las relaciones con la realidad exterior e interior.

No hay duda de que tales planteamientos, textualizados por partes en varios episodios, bajo formas de acción y de relaciones variadas, constituyen un conjunto organizado y orientado a exponer los problemas y analizar los elementos de una teoría del conocimiento, en una dimensión pragmática y a la vez teórica. No puede ser casualidad que tantos episodios aborden temas conexos, si no se han planificado los problemas internos y las relaciones que estudia la epistemología. Un análisis sintáctico de los episodios y de las formas textuales puede descubrir los valores semánticos y pragmáticos y señalar qué tipo de relación mantienen los episodios entre sí bajo las anécdotas que parecen alejadas. Las relaciones entre varios episodios no se basan en la igualdad de los conflictos, en la permanencia de los mismos personajes y las mismas funciones, pueden basarse en otros hechos: que tengan la causa común de ilustrar la misma idea, que tengan referencias discursivas próximas o incluso que cuenten la misma historia, o la articulen de forma paralela, que mantengan los mismos personajes en las mismas relaciones estructurales, etc.

Hace tiempo llamó mi atención el hecho de que las relaciones subyacentes fuesen iguales o paralelas en varios episodios y todas centradas en problemas gnoseológicos; es un tema inesperado en un relato literario narrativo (quizá no tanto en uno dramático, si pensamos en obras como una tesis o un tema único, que encarnan un tema en uno de los personajes, como Edipo, Hamlet, La vida es sueño, etc., y pueden ejemplificar casos sobre el conocimiento, la responsabilidad, la duda, la justicia, etc., por medio de los personajes a los que convierte en tipo, y pude comprobar que, por ejemplo, los cuatro episodios que citamos no parecían anécdotas sueltas, reunidas al azar, sino que su conjunto se articulaba en torno a un motivo nuclear y transversal en El Quijote: la trayectoria de la cordura a la locura, previa al inicio del discurso y 
manifestada textualmente, de una parte, y la trayectoria de recuperación de la cordura que llevará al desenlace y, según creo, se inicia en la cueva de Montesinos, por las dudas que plantea.

Al proyectar este enfoque sobre el episodio de la cueva de Montesinos y, al relacionar el conocimiento con sus coordenadas cronotópicas, principalmente con el tiempo (Bobes,1994: 125-143), se mostró que tal aventura, una de tantas que le salen al paso al caballero, como las bodas de Camacho, la del primo humanista, la de los rebuznos de los alcaldes, y tantas otras, adquiría un sentido especial porque eran pasos en el viaje de la fantasía a la realidad, y en el viaje de vuelta de la locura a la cordura, es decir, la trayectoria que había recorrido don Quijote en los libros de caballerías hacia la locura y de la locura a la razón y muerte del personaje en el desenlace. La estructura de muchas novelas es la de un viaje físico de ida y vuelta en el que el personaje toma conciencia de sí mismo y de la realidad física, social y humana que lo rodea: el viaje es el esquema sobre el que se organizan novelas de viaje, de formación, de aventuras, de intriga, etc. Aparte del viaje físico más amplio, desde su pueblo de La Mancha hasta Barcelona y la vuelta, El Quijote organiza algunas variantes, como una primera salida corta, y una segunda más amplia con viaje de ida y vuelta, algunas desviaciones y algunas paradas, etc. en las que don Quijote y Sancho se topan con muchas y variadas situaciones.

El episodio de Montesinos se hace medular en la novela (por eso suscita tantos comentarios, que hasta Cide Hamete sale a poner orden), porque abre el largo proceso de vuelta del héroe a la razón, y gira su trayectoria hacia la realidad, con la consiguiente desaparición del mundo fantástico en el que el caballero se había instalado desde el comienzo de la novela. El camino de la cordura a la locura la resume el narrador afirmando que a don Quijote, de tanto leer, se le había secado el cerebro y pasó a imaginaciones que irá detallando el texto; el camino inverso de la locura a la razón se jalona de episodios en los que se duda de la realidad, de la razón, de los sentidos, del conocimiento, de la certeza, etc., hasta 
alcanzar el uso pleno de la razón, en el capítulo final de la obra. La primera parte de los viajes está llena de euforia y entusiasmo, mientras que las vueltas suelen ser, por de pronto melancólicas, y hasta tristes, faltas de ilusión como final de proyecto y como camino a lo conocido.

Poco a poco, van apareciendo relaciones entre episodios, más allá de las anecdóticas, con algunas variantes, y se puede comprobar que hay un conjunto de personajes y de aspectos que plantean problemas epistemológicos: cada uno de esos episodios formula unas posibilidades concretas al poner en juego un abanico bien amplio de posibilidades sobre la función que tiene la realidad y la fantasía, la verdad y la mentira, la palabra y la información, la verosimilitud y el absurdo, la deducción, el discurso, la negación, las alternativas, etc. El episodio de la cueva de Montesinos, en la situación espacial fuera /dentro centra el problema en las referencias al tiempo: una hora / tres días, y hará reflexionar a don Quijote sobre los límites de su fantasía, si quiere introducirla en la realidad de sus amigos: ¿es verdad lo que él vio dentro de la cueva, si queda fuera de toda verosimilitud en el tiempo real? El caballero, a partir de esa imposible verificación, se instala en la duda y pierde la seguridad que sobre su propio ser y sus capacidades tenía en la primera parte de su historia. ¿Qué ha fallado: la realidad, su captación por medio de los sentidos, la palabra que verbaliza la experiencia, la comunicación, la interpretación...? Las posibilidades son muchas y el texto no descarta decididamente ninguna, oscila en ambigüedades continuas, que no se resuelven, de modo que el lector comprende el problema, pero no ve su solución.

Desde esta lectura de las anécdotas y de las posibilidades para el conocimiento, se puede ver cómo plantea Cervantes algunos problemas en los cuatro episodios: el de Sansón Carrasco y su escudero Tomé Cecial; el de la cueva de Montesinos; el de la historia del Caballero del Verde Gabán; y el tema transversal del encantamiento de Dulcinea, que se prolonga por toda la segunda parte de la novela y sume a don Quijote en el desconcierto 
hasta terminar diciendo a la duquesa: "solo Dios sabe si Dulcinea existe, encantada o desencantada" (516). Estas historias muestran muy claramente la atención que Cervantes dedicó a los problemas del proceso gnoseológico y a sus pasos y a las relaciones entre sus elementos.

Aparte de las diferencias circunstanciales de los cuatro episodios, hay que tener también en cuenta que los sujetos del conocimiento tienen diferentes situaciones y además varían de un momento a otro: su actitud, su confianza, la seguridad en sí mismos y en los demás; don Quijote y Sancho y sus compañeros circunstanciales abordan con diferente actitud las situaciones sucesivas y su posibilidad de entenderlas y así actúan también los otros personajes. Además del proceso de conocimiento es necesario atender a la evolución de los personajes; el conocimiento de los hechos se complementa con el análisis de los sujetos cognoscentes; al conocimiento abstracto hay que añadir las actitudes de los sujetos, condicionadas por su disposición, por sus saberes, por el fin que buscan, pragmático o teórico, por su función de sujetos activos o de observadores, etc. La disposición de don Quijote ante el conocimiento no es la misma antes y después de entrar en la cueva de Montesinos, no es la misma si el objeto del conocimiento es un personaje cualquiera o es su dama: la confianza inicial se transforma en duda dolorosa y en desconfianza en las posibilidades de alcanzar la certeza.

En el episodio de Montesinos asoma sutilmente otro problema que suspende un tanto el ánimo del lector sin darle una explicación definitiva que acabaría con todas las dudas. Cuando don Quijote cuenta lo que pasó dentro de la cueva él parece creerlo y parece actuar de buena fe; cuando le hacen ver que no pudo pasar, porque el tiempo no daba para tanto, se queda perplejo y desconfía de la experiencia. Hasta ahora la oscilación se plantea entre esos dos extremos, ¿lo que cuenta don Quijote es verdad o es mentira, se identifica con la fantasía y sus verdades, o se identifica con la realidad pragmática, dentro de las convenciones que plantea el relato? A ninguno de los oyentes se le ocurre pensar 
que el caballero pueda mentir, y únicamente el autor descubre sin mucho énfasis que sólo a la hora de su muerte se retractó de la historia y reconoció que había mentido, con el agravante de que no se había dejado llevar de la locura, sino de la superchería, pues lo contó por parecerle que "convenía y cuadraba bien con las aventuras que había leído en sus historias" (224). Y hay otra alusión a una posible mentira y retractación de don Quijote en el episodio con Maese Pedro, cuando le ruega que pregunte al mono si es verdad lo que pasó en la cueva de Montesinos: Sancho cree que "todo fue embeleco y mentira, o por lo menos cosas soñadas." Don Quijote responde que "todo podría ser, pero yo haré lo que me aconsejas, puesto que me ha de quedar un no sé qué de escrúpulo" (238). Esto significa que don Quijote, que de otro modo se hubiera enfurecido ante las palabras y las dudas de Sancho y hubiera reaccionado a palos sobre el escudero, pudo mentir y tiene algún escrúpulo; esta actitud socava totalmente la idea que el lector se había formado sobre su honestidad, que permitía creer en la locura, pero no en un engaño más o menos deliberado.

Resulta muy inquietante esa alusión a la actuación de don Quijote, porque introduce una duda acerca de su modo de ser: el caballero que recibe tantos palos y soporta un trato físico tan cruel por mantener sus ideas, ¿actúa de buena fe?, ¿es capaz de inventar y contar todo lo que cuenta a la salida de la cueva para sentirse halagado con las palabras de Montesinos, o para dejar admirados a sus amigos?, ¿es tan ingenioso, y a la vez ligero, para seguir la mentira de Sancho en el encantamiento de Dulcinea y seguir la broma de su vida en la cueva? Los cimientos de la trama se sacuden en este episodio. Un lector atento puede acceder a la estructura de un relato en el que el narrador se disocia de su modo de contar cuando quiere, las actitudes se acogen a la duda, los personajes se construyen y se deconstruyen, la verdad y las mentiras son posibles, se superponen, no se descartan, etc. La duda, no la seguridad, empieza a instalarse en la trama del relato y deja al lector en la sorpresa y a la expectativa. 
Lo mismo pasa en los otros episodios: no es posible que Dulcinea, tan idealizada en la imaginación, sea la tosca aldeana que Sancho señala y, para mayor inestabilidad, no parece verosímil que don Quijote vea a su amada en la cueva con las ropas y con los modales que le asigna el encantador Sancho; no es posible que el Caballero del Bosque sea Sansón Carrasco y su escudero sea Tomás Cecial, porque cómo se explicaría un ataque por parte de un vecino con el que se llevan bien, que no es su enemigo ni por pienso: ¿por qué iba Sansón a buscar pelea, si tenía buen trato y de amistad con don Quijote?

Las relaciones se plantean de modo diferente entre los sujetos y los objetos del conocimiento, el contenido y las circunstancias. Si seguimos analizando como sujetos a Sancho y a don Quijote, sobre todo a éste, podemos observar cómo cada episodio, aunque coincida en su sentido con los otros, atiende a un aspecto concreto y se enfrenta a un determinado tema y a una forma diferente de enfocarlo, además generalmente textualiza las razones de los cambios en cada caso. Puede comprobarse en cada caso.

A Sansón lo conocen bien tanto Sancho como don Quijote, ya que es, como Tomé Cecial, su vecino; la experiencia suele ser fuente para el conocimiento, pero puede quedar desvirtuada, si fallan los sentidos, que advierten la realidad, si no falla la memoria, en su función de conservar el recuerdo de la realidad, como punto de partida para el proceso de conocimiento. El recuerdo llevaría al reconocimiento del falso caballero y de su escudero, pero el texto incluye varias alteraciones que impiden la percepción: se anula el sentido de la vista, pues cuando aparecen Sansón y Tomé es noche oscura, y los otros dos los oyen pero no los ven, ya que están un tanto alejados, no comparten espacio, no están cara a cara; cuando por la mañana se ponen a la vista y hay luz, la armadura del caballero impide ver su cara y las falsas narices del escudero cambian su fisonomía: los sentidos del oído y de la vista no pueden cumplir su función de acceder a la reali- 
dad inmediata y de facilitar el reconocimiento en el encuentro de caballeros y escuderos.

El engaño a los ojos (armadura, narizotas) distorsionan el conocimiento e impiden el reconocimiento. Ni la experiencia ni la memoria garantizan nada si se modifican las circunstancias, si el objeto se aleja de su espacio, si se altera el aspecto físico, si se sustituye la lógica racional por la lógica de la perplejidad o del absurdo, si la realidad se oculta a los sentidos o se presenta de modos diferentes. La situación desemboca en la duda sobre el ser, y la actuación de los sentidos no encaja en el proceso: el conocimiento es también reconocimiento que confirma lo que se recuerda y los esquemas en los que cobra sentido la experiencia. La lógica de la perplejidad sobre los cambios prevalece sobre la lógica de la razón deductiva: don Quijote y Sancho no reconocen a sus vecinos y se instalan en la duda. Y cuando por lo que cuenta Tomé y cuando pueden verlos mejor al amanecer, aunque tapado el uno, narigudo el otro, la duda afecta a la palabra, pues ellos dicen ser el Caballero del Bosque y su escudero, no Sansón y Tomé. Además de la experiencia y sus circunstancias, la palabra distorsiona el conocimiento y ni don Quijote ni Sancho pueden confirmar su verdad, ni siquiera sus sospechas. El episodio de Sansón analiza el papel de los sentidos, la vista y el oído, en el proceso de conocimiento.

El episodio del Caballero del Verde Gabán plantea la revisión de un problema gnoseológico con sus propias circunstancias; no parte de un conocimiento anterior, no se trata de alcanzar un posible reconocimiento de un sujeto o de un prototipo en un individuo, se parte de un primer encuentro con signos externos que permitan encajar el conocimiento sobre otro sujeto: don Quijote y Sancho no conocen a don Diego, ni éste los conoce a ellos, y después de varios días juntos, intentan conocerse y aclararse, hablar y dar datos, y al final se separan sin saber cómo son. Naturalmente cada sujeto tiene una trayectoria y un conjunto de conocimientos que le sirven de molde para encajar a los nuevos: don Diego tiene un concepto de la vida, de la familia y de su casa, de 
los amigos, de las ocupaciones de un hidalgo, de un entorno en un pueblo manchego, etc.; sabe muchas cosas, maneja con soltura prototipos, excluye fantasías, como la de la caballería andante, y rechaza todo lo que no entre en su visión del mundo como pequeño burgués. Desde la plataforma propia, que ha conseguido con una instrucción social y con una formación pedagógica de su clase social, se adentra en otras circunstancias y en otros posibles conocimientos y los admite si están garantizados, o los rechaza si no encajan en sus modos.

Don Diego se presenta de improviso en mitad del camino y se da a conocer primero a partir de los sentidos, por su apariencia, su vestimenta y sus palabras, que no generan conocimiento cierto, sino asombro e impiden colocarlo como un prototipo social conocido. Su palabra, que describe o interpreta su modo de ser, da testimonio de sí mismo, desde su punto de vista y, por supuesto, mediante juicios muy favorables: don Diego tiene sabido el esquema de su modo de ser y lo tiene muy bien valorado como modelo de gracia: se presenta tan bien que Sancho deduce que es un santo; don Quijote, más apercibido de las autoalabanzas, concluye que es un hombre sin ninguna grandeza, mediocre, de poco espíritu, un pequeño burgués, cazador medianejo, de pocos alcances, con su hurón atrevido y un perro de raza pacífica. A partir de esta presentación, tan poco definida, excepto para el mismo don Diego, tan poco sólida y tan poco convincente, la experiencia del trato en los días en que conviven en el camino y en casa del hidalgo, no sirve para mucho más y, tanto el caballero como el hidalgo, se separan sin llegar a conocerse. Se puede ampliar la inseguridad a otros detalles de esta relación, que ya hemos revisado en otro estudio (Bobes, 2012: 126-147) y se deduce lo mismo.

Muchas veces los alumnos me han preguntado cuando explico interpretaciones sobre una lectura de este tipo, más allá de los hechos y funciones de la anécdota inmediata, si el autor es consciente de que usa recursos para convertir una historia de sucesos en un campo de ideas, o bien si éstas son un resultado que deriva de la lectura del crítico. Lo que cuenta Cervantes es que 
don Quijote encontró a un caballero raro de apariencia, vestido de verde y que va con él unas horas, que encuentran una carreta con leones y don Quijote los desafía, mostrando su locura, a la vez que su valentía insensata; don Diego lo invita a su casa, donde están él y Sancho unos días, viven pequeñas anécdotas de vestimenta y de comida en el día a día, hablan sobre diversos temas, de poesía y de convivencia, y al final ni don Diego ni don Quijote son capaces de aclararse sobre el otro, y el episodio se cierra sin ningún conocimiento seguro, definido, válido, del otro. Don Quijote piensa que la única posibilidad de que don Diego y su familia acaben por saber qué es el glorioso cuerpo de la caballería andante, es que Dios les aclare la verdad, no parece humanamente haya otro camino para ilustrarlos o convencerlos, y don Diego se queda con sus perplejidades, lo mismo que don Lorenzo, su hijo.

Otro de los episodios que se enfrenta a temas gnoseológicos es el encantamiento de Dulcinea: hay que partir de la imaginación y locura de don Quijote sobre el mundo fantástico de la caballería andante, donde la dama constituye un prototipo y una figura perfecta en su apariencia y en sus hechos. En este caso, don Quijote parte de la experiencia mínima visual de la moza del pueblo vecino, Aldonza Lorenzo, que amplía generosamente con datos de lectura hasta alcanzar el prototipo de Dulcinea del Toboso, la más hermosa dama que puebla el mundo de la caballería andante, según afirma, sostiene y defiende su caballero: experiencia de vida y fantasías de lecturas sirven de fuentes para el conocimiento de don Quijote sobre su dama; no hay un conocimiento pragmático, basado en la experiencia de los sentidos, sino que se actúa sobre lo que dicen los textos caballerescos, $\mathrm{y}$, por tanto, el conocimiento proviene de prototipos del mundo fantástico. La habilidad y picardía de Sancho para salir de sus propios líos, traslada al mundo de la realidad las posibilidades de los encantadores que pueblan el mundo de ficción, y espera que don Quijote admita sin dificultades sus fantasías, como él admitió las de su amo; la situación se hace compleja y desco- 
loca al caballero, y también al lector. La lógica de la perplejidad y del desconcierto, que surgía en los otros episodios de algunas contradicciones, por ejemplo las temporales al salir de la cueva, se hace presente también en éste; se oculta la lógica racional, en preguntas y respuestas, en todo el relato y desde luego, no se consigue ningún tipo de certeza; el marco de la realidad no acoge los hechos de ficción; don Quijote no acepta que su amada y sus damas sean aquellas toscas campesinas que brincan con soltura; sus conocimientos, que pueden tener origen en el mundo ficcional de la caballería, exigen un mínimo de correspondencia para identificarlos en la realidad empírica.

El episodio de la cueva de Montesinos hace su planteamiento tanto temático como semiótico de una manera original, como ocurre con cada uno de los que estamos revisando. De antemano la cueva es conocida por rumores, leyendas, por cosas maravillosas que se dicen de ella en los alrededores: la noticia de la cueva y sus maravillas le viene a don Quijote por la palabra, los rumores, los relatos: todo atrae su atención y quiere comprobar la verdad. Merece la pena seguir paso a paso cómo se camina por esos bordes de ficción, si se pretende alcanzar conocimiento y certeza. El panorama se construye con minuciosidad, discurre poco a poco, pero no se encamina a ninguna parte: frente al asombro y al desconcierto de otros episodios, el de la cueva de Montesinos desemboca en la inseguridad, en la imposibilidad de verificación, y, sobre todo en la duda, que se proyectará por varios capítulos, revisando posibilidades. Desde la salida de la cueva, don Quijote inicia el camino hacia su muerte como personaje de relato: cuando recupere la cordura perderá su vida de ficción.

La visita a la cueva se desarrolla en los capítulos XXII y XXIII, pero se anuncia ya en el XVIII (168), cuando don Quijote se despide de sus anfitriones don Diego y don Lorenzo de Miranda. En el cuadro de la despedida queda de manifiesto la conexión con el tema de la experiencia como inicio del saber. No cabe duda de que un conjunto de motivos plantean e ilustran problemas sobre el conocimiento, sus elementos y sus circunstancias, aunque cada 
uno es autónomo en su anécdota y atiende un tema concreto de las relaciones entre el Sujeto, el Objeto, la Realidad, la Fantasía, la Información, la Certeza, etc; todos se conectan y avanzan conjuntamente remitiendo unos a otros, temática y discursivamente.

Los cuatro episodios coinciden en su temática gnoseológica y se diferencian en las circunstancias de su origen y su manifestación: Dulcinea es una fantasía de don Quijote, y no puede abrirse a ningún conocimiento, el caballero la ve cada vez más problemática hasta dudar de su existencia: sólo Dios sabe si Dulcinea existe. Sancho contribuye con su patraña al identificarla con una labradora y don Quijote alude a ella como habitante del reino de los encantados, la cueva de Montesinos, donde alterna con Durandarte, Belerma y Montesinos. Los personajes de El Quijote se dan la mano por esos andurriales, directamente o en el recuerdo y contribuyen a la misma ceremonia de la confusión.

El episodio de la cueva de Montesino pasa de la palabra (rumores, maravillas, etc.) a una versión fantástica que le da don Quijote y que él mismo considerará inverosímil a la vista de las discordancias entre lo que cree haber vivido y el tiempo real fuera de la cueva. La posibilidad de que don Quijote mienta y presente como real lo que inventa a partir de sus mundos literarios (caballerías y romancero), asoma, se insinúa, pero es impensable para Sancho, que se desliza por la idea del desconcierto cuando al final del capítulo XXIV, después de oír a su amo razonar impecablemente, respecto a otros temas, se despacha diciendo: “ ¿es posible que un hombre que sabe decir tales, tantas y tan buenas cosas como aquí ha dicho, diga que ha visto los disparates imposibles que cuenta de la cueva de Montesinos?" (229). El remate a esta reflexión es un tanto sorprendente porque Sancho deja la puerta abierta a esa posibilidad con un escueto resumen: "ahora bien ello dirá." Nos sorprende que es la misma expresión que utilizará Clarín cuando cuenta que don Fermín vislumbra posibilidades en sus pretensiones de seducir a la Regenta: el hecho parece imposible, pero ello dirá, como si el relato tuviese vida propia. La realidad y los encantamientos, su vínculo con la sen- 
satez y la locura, se abren a otra posibilidad, el engaño, la mentira, y chocan de frente con el modo de ser del caballero: ¿será capaz de mentir?, ¿será capaz de inventar fantasías y proponerlas como experiencias?

El caso de Sansón que viene de la experiencia y desembocaría en el reconocimiento, vuelve a la realidad cotidiana, aunque con el barniz de la manipulación de la verdad que se achaca a los encantadores y magos que siguen y persiguen a don Quijote. Éste es un sujeto pasivo, que encaja lo que le dicen y un loco crédulo capaz de abrir su mundo propio de fantasías a las propuestas de los demás, por absurdas que sean.

Se ve clara la conexión de la historia de don Quijote y el Caballero del Verde Gabán, con los análisis epistemológicos, pues se plantea textualmente la posibilidad de que un hombre pueda conocer a otro y situarse en la certeza de ese conocimiento: ¿pueden dos sujetos, los dos raros, don Diego de Miranda y don Quijote, conocerse a partir de la experiencia que ofrece el trato personal, en un tiempo y en un espacio? Aquí no hay encantadores, no hay fantasía, no hay afán de engaño ni simulaciones, no hay tampoco distorsión de los datos ni de los sentidos: todos ven bien las apariencias, todos oyen claramente las palabras $y$, sin embargo, la conclusión es que no, que el conocimiento es imposible porque el marco de referencias y los prejuicios en que don Diego está situado es que los caballeros andantes no existen, y el concepto del pequeño burgués que tiene don Quijote para situar a caballeros pacatos, de vía estrecha, como don Diego, es el desprecio, él no necesita conocerlos, no le merece la pena escucharlos, ni mantener su amistad, así que don Diego, su familia y su pueblo desaparecen del horizonte de la novela definitivamente, mientras don Quijote y Sancho vuelven al camino en busca de aventuras un poco más gloriosas. Quizá este episodio es el único en el que don Quijote se muestra un tanto cruel: su ideal no es el de pequeño burgués, con un hurón y un perro perdiguero; don Quijote tiene un galgo corredor, que tampoco es gran cosa, pero sí más presentable. 
El relato queda detenido en este punto de perplejidad y da entrada a otro episodio en el que se tratará de aclarar si la fuente para el conocimiento puede ser otra y si los ámbitos del saber pueden estar alejados en otras posibles relaciones, una vez que se descarta la experiencia, que ha fallado en el episodio de Sansón, y descartada también la posibilidad de conocer a los demás, si no responden a los esquemas previos, o a los prototipos culturales de cada uno. Quizá sea posible una adecuación en otros extremos.

Situados los episodios en su propia perspectiva semántica y argumental, puede seguirse el orden y alcance de cada uno en el conjunto sintáctico: don Quijote ha diseñado su hoja de ruta, quiere ir a las justas de Zaragoza, pero "primero debía de entrar en la cueva de Montesinos, de quien tantas y tan admirables cosas en aquellos contornos se contaban" (176). Antes de poner fin al análisis del "conocimiento por la experiencia directa," que ha presidido la relación con don Diego y su familia, y antes de tomar el camino que lo aleja de la casa de los Miranda, donde se come bien, pero se discurre poco y de forma tópica, accede al ámbito de las aventuras que se presentan en los caminos, por azar, no planificadas, como será el episodio de las bodas de Camacho, el episodio del paje que busca trabajo en el ejército, el cuento de los rebuznos, etc. Don Quijote anuncia la historia que vivirá en los capítulos XXII al XXIIII, que se centra en el papel de la fantasía y su modo de entender o de contar el tiempo dentro de la cueva, en contraste con la experiencia.

Los episodios se suceden y alternan en la trama del Quijote en las dos vías: las buscadas y las que salen espontáneamente al encuentro del caballero en su deambular por los campos de la Mancha. Admitiendo el carácter ocasional de muchos episodios, hay una serie de ellos que no parecen casuales, pues, al ponerlos en relación de sentido, parecen constituir un muestrario de casos para analizar los problemas que ofrece el proceso de conocimiento: una secuencia de aventuras recoge o alude a problemas epistemológicos sobre el sujeto o el objeto, sobre sus posibilidades 
de relación y sus funciones, sobre el papel de los sentidos, de la memoria, etc. El conjunto de tales episodios parece dibujar una teoría epistemológica, tal como vamos analizándolos.

El conocimiento es un proceso semiótico que se establece entre un Sujeto y un Objeto. El Sujeto es siempre humano, el Objeto puede ser humano o no. La relación entre ambos es iniciada por el sujeto, y cuenta con una serie de elementos y pasos que se integran en acciones, palabras y esquemas verbales: el sujeto aporta conocimientos previos y memoria para situar al objeto; tiene creencias y aptitudes individuales: los sentidos, una presencia, una cultura, una fantasía, etc. que le permiten saber qué está haciendo y qué finalidad persigue; tiene la palabra, el discurso y una formación semiótica que le conduce a interpretar lo que ve como signos de un sistema, tanto para asimilarlo como para transmitirlo, o rechazarlo; tiene posibilidades de acercamiento a la realidad a través de la percepción de los sentidos; y tiene unas formas determinadas de reconocimiento para relacionar los objetos y las situaciones, y poder comprenderlos, insertándolos en su sistema.

Cada episodio plantea un aspecto de las situaciones epistemológicas: en uno se revisa la relación Sujeto-Objeto, en otro los elementos que intervienen en esa relación y la hacen objetiva: los sentidos, como vías de acceso a la realidad y enlace con el pensamiento; el cronotopo, es decir, las coordenadas y el marco donde se sitúa el proceso del conocimiento; la palabra, como forma que permite dar forma objetiva al conocimiento, como expresión y también alcanzar procesos de comunicación.

Cuando los sentidos no pueden ser utilizados (por falta de luz, o por la distancia que impide la identificación del otro, por el engaño o enmascaramiento), como hemos comprobado en el episodio de Sansón Carrasco, o cuando la falta de marco compartido impide conocer prototipos que diseñen una figura o integren los datos, como ocurre en el caso de don Diego de Miran$\mathrm{da}$, que no reconoce la existencia de caballeros andantes $\mathrm{y}$, por 
tanto, no puede aceptarlos como objetos del conocimiento real, ni puede situar a don Quijote en su marco propio; o cuando la información sobre una realidad es falsa y no hay modo de elegir un camino claro y eficaz para lograr la certeza: Sancho afirma que ve a Dulcinea y a sus damas en la figura de la campesina y sus compañeras, desconcierta a don Quijote que se debate entre el testimonio verbal de su escudero y lo que él propone, que no coinciden en absoluto, $\mathrm{y}$, por consiguiente se relativiza toda posibilidad de conocimiento verdadero. Inseguridades, oscilaciones, dudas metodológicas, etc., constituyen impedimentos parciales $\mathrm{y}$ a veces totales en los procesos que conducen al saber.

Las vías del conocimiento suelen ser un camino desde la realidad hacia el saber, en cuyos pasos, de acercamiento y alejamiento, intervienen los sentidos, las creencias y la palabra; si una de estas vías falla, el conocimiento de un objeto o de otro sujeto resulta inasequible. El Sujeto dispone de sus sentidos, de su información previa, de su capacidad de deducción, y de sus conocimientos semióticos para la expresión y para la comunicación, y dispone también de las formas, las apariencias y el ser del objeto para acceder a su conocimiento y a las certezas adecuadas.

Todos estos medios y posibilidades van analizándose en los episodios del relato; el de la cueva de Montesinos enfrenta, basándose en su marco temporal, la fantasía con la realidad, pero no en abstracto, sino tal como están en don Quijote, en Sancho y en el primo humanista; cada uno afronta los hechos contando con su propia mochila de experiencias y actitudes: don Quijote cuenta lo que cree haber visto dentro de la cueva, alude a conversaciones con personajes a los que conoce por lecturas, afirma que ha visto a Dulcinea encantada, como Sancho se la había presentado. Sancho escucha el relato de su amo desde su experiencia de magos y encantadores y desde sus interesados embustes sobre el encantamiento de Dulcinea, y el primo humanista saca su sentido crítico, y advierte una discordancia inmediata en el tiempo de dentro y el de fuera; algo falla al conjuntar las diferentes posibilidades, con las que actúan los sujetos. Las derivaciones 
de los distintos supuestos son muchas y conviene analizarlas por separado para comprobar su relieve en el conjunto de la historia.

A finales del cap. XVIII de la segunda parte, al terminar el episodio del Caballero del Verde Gabán, se advertía la imposibilidad de alcanzar un conocimiento intersubjetivo cuando los modelos y los marcos de cada sujeto no existen o están muy distanciados. A continuación, el relato se adentra en otros problemas del conocimiento. En la tal cueva don Quijote va a entrar solo, con su bagaje de historias y personajes conocidos, de experiencias adquiridas en las lecturas de romances y novelas de caballería, y además con la seguridad de que nadie puede discutirle lo que cuenta, porque nadie ha bajado a la sima con él. Y efectivamente nadie le discute las anécdotas; las objeciones se desvían a uno de los elementos donde sí pueden plantearse dudas: el tiempo. La verificación de los tiempos dentro y fuera, la capacidad del tiempo para admitir historias cortas o largas, constituye la piedra de toque en este caso concreto.

Vale la pena seguir paso a paso el proceso para comprobar cómo se van planteando los problemas: en el cap. XXII (202) al cerrar el episodio de las bodas de Camacho y despedirse de los novios,

pidió don Quijote al diestro licenciado le diese una guía que le encaminase a la cueva de Montesinos, porque tenía gran deseo de entrar en ella y ver a ojos vistas si eran verdaderas las maravillas que de ella se decían por todos aquellos contornos. El licenciado le dijo que le daría a un primo suyo, famoso estudiante y muy aficionado a leer libros de caballerías, el cual con mucha voluntad le pondría en la boca de la mesma cueva, $[\ldots]$ y despidiéndose de todos, se pusieron en camino tomando la derrota de la famosa cueva de Montesinos. (205)

Ningún otro análisis sobre un aspecto epistemológico había sido preparado textualmente con tanto detalle, ninguno crea tantas expectativas sobre lo que se deriva de la situación creada y 
ninguno alcanza un resultado tan relevante en la estructura del relato, puesto que es nada menos que el inicio del camino hacia la cordura de don Quijote y el desenlace de la trama.

Aparte del caballero y del escudero, que son bien conocidos por el lector a estas alturas del relato, tanto en su historia como en sus relaciones, y que, por tanto, están abiertos a cualquier añadido y a una interpretación completa, se incorpora un tercero, el primo humanista, figura que en aquella época sería muy nueva, y que era realmente necesario en el episodio para plantear razonablemente el problema del conocimiento y de la verdad, remitiéndola a la experiencia inmediata. Don quijote y Sancho pueden competir en encantamientos y en historias consabidas de fantasías; el primo aportará el argumento realista, inmediato, decisivo, experimental: el tiempo cronológico. Seguimos paso a paso su intervención, porque creemos que Cervantes construyó su papel con minuciosidad y empeño hasta encajarlo y ofrecerlo perfecto.

Don Quijote preguntó al primo "su profesión y estudios; a lo que él respondió que su profesión era ser humanista" y para que el lector compruebe que no miente, en las páginas 218 y 219, el primo hace una relación de libros humanistas, que el narrador transcribe con cierto humor, al pasar de la prosopopeya de la presentación a la trivialidad de los temas que tratan. Queda así bien presentado el primo y se augura lo que de él cabe esperar.

A la noche, el trío se alberga en una pequeña aldea, a unas dos leguas de la cueva, y a las dos de la tarde del día siguiente llegan a la boca de la tal cueva; en el pueblo se pertrechan de lo necesario para bajar a la cueva, es decir, atienden a la parte material de la aventura para situarla en sus dimensiones completas, pues don Quijote estaba ya bien decidido por lo que se refiere a las intenciones y al ánimo.

Sancho y el primo ayudan a bajar a don Quijote y se quedan arriba; comentan lo que puede pasar dentro, donde no alcanza su vista: ¿cómo lograrán aclarar lo que pase, si ha de contarlo 
don Quijote, cuya fantasía está tan intervenida por lecturas, tan mediatizada por la fantasía y por sus propias aventuras. Los pasos se miden con detalle: después de que "los dos le ataron fortísimamente con las sogas" (208), don Quijote se encomienda a Dios y a Dulcinea, y baja, colgado de la cuerda, hasta agotar las cien brazas que habían comprado, si bien a partir de las ochenta, la cuerda no parecía sustentar peso; se supone que don Quijote había recalado en un entrante y que la cuerda se enrollaba a su lado, por su propio peso, a medida que la sueltan los de arriba, y así se verificará cuando tiren de la cuerda para sacarlo; nada se había roto, nada se había desatado, sólo se había parado el descenso: la cueva tenía la profundidad de ochenta brazas, y don Quijote había llegado al fondo, o bien un entrante lateral había servido de asiento al caballero, antes de alcanzar la profundidad total de la cueva; la soga siguió bajando hasta donde buenamente llegaba, según los de arriba iban comprobando, y don Quijote se queda dormido un rato.

Con todo este trajín se entretuvieron como media hora y al cabo, se retoma el relato punto por punto: los de arriba empezaron a recoger soga con mucha facilidad y sin peso alguno, señal que les hizo imaginar que don Quijote se había soltado y se quedaba dentro, herido, inconsciente o dormido, pero al alcanzar, a su parecer, poco más de las ochenta brazas, sintieron peso, lo que les produjo gran contento, como testimonio de que el caballero seguía atado. Finalmente vieron distintamente a don Quijote, a quien Sancho dio voces, pero no respondía palabra y, sacándolo del todo, vieron que traía cerrados los ojos, y parecía dormido. Tendiéronlo en el suelo y desliáronlo, y con todo no despertaba; pero tanto lo volvieron y revolvieron, sacudieron y menearon, que al cabo de un buen espacio volvió en sí, desperezándose, como si de algún grave y profundo sueño despertara y dijo: "Dios os lo perdone, amigos: que me habéis quitado de la más sabrosa y agradable vida y vista que ningún humano ha visto ni pasado [...]" (210).

Al entrar en la realidad, el primer paso lo da la necesidad física: "pidió que le diesen algo de comer, que traía grandísima 
hambre $[\ldots] \mathrm{y}$, sentados todos tres en buen amor y compaña, merendaron y cenaron, todo junto." Dieron por atendida la necesidad y dijo don Quijote, cerrando el capítulo de los hechos: "No se levante nadie, y estadme, hijos, todos atentos" (210).

Así da fin el cap. XXII y empieza el XXIII, proponiendo con toda solemnidad y con la precisión necesaria, el marco temporal: "Las cuatro de la tarde serían..." Don Quijote inicia un relato que deja caer datos y motivos que orientarán la historia hacia su desenlace, pues el lector se enfrenta al primer paso hacia la cordura del héroe, a partir de la duda que plantea la discordancia de tiempos dentro y fuera de la cueva. Siguiendo la lectura del texto se va descubriendo poco a poco la importancia del episodio, sus aclaraciones que exige, los ecos que produce, las dudas y reflexiones que suscita sobre su sentido en la trama.

Don Quijote hace un relato minucioso y con detalles que apuntilla Sancho cuando le parece, como cuando apunta que el puñal con que Montesinos sacó el corazón de Durandarte para llevárselo a Belerma debía de ser de Ramón de Hoces, el sevillano. Don Quijote apunta en la dirección que luego prevalecerá, basándose en la verosimilitud que exige el tiempo: "no sería de ese puñalero, porque Ramón de Hoces fue ayer, y lo de Roncesvalles, donde aconteció esta desgracia, ha muchos años; y esta averiguación no es de importancia, ni turbia, ni altera la verdad y contesto de la historia" (213).

Siguiendo con objeciones temporales, el primo expone una duda muy razonable:

Yo no sé, señor don Quijote, cómo vuestra merced en tan poco espacio de tiempo, como ha que está allá abajo, ha visto tantas cosas y hablado y respondido tanto.

- ¿Cuánto ha que bajé? -preguntó don Quijote.

-Poco más de una hora -respondió Sancho.

-Eso no puede ser -replicó don Quijote- porque allá me anocheció y amaneció, y tornó a anochecer y amanecer tres veces; de modo 
que, a mi cuenta, tres días he estado en aquellas partes remotas y escondidas a la vista nuestra.

-Verdad debe de decir mi señor -dijo Sancho-, que, como todas las cosas que le han sucedido son por encantamiento, quizá lo que a nosotros nos parece un hora, debe de parecer allá tres días con sus noches.

-Así será -respondió don Quijote. (219)

Así queda planteado punto por punto el tema: ¿el tiempo que vive don Quijote dentro de la cueva corre de modo diferente al tiempo en el que viven fuera Sancho y el primo?, ¿todos dicen verdad?, ¿puede ser cosa de encantamiento, si realmente dentro de la cueva la vida transcurre entre encantadores y encantados?

Todo queda en un puede ser, y, agotada esta vía, sin encontrar salida cierta, Sancho abre otra, la de una posible mentira por parte de su amo, y la expone primero negando lo anterior, luego, volviendo a los encantadores. Todo un proceso de insinuación, de afirmaciones, de avances y retrocesos, en juego con el primo:

Perdóneme vuestra merced, señor mío, si le digo que de todo cuanto aquí ha dicho, lléveme Dios, que iba a decir el diablo, si le creo cosa alguna.

- ¿Cómo no? ¿dijo el primo-, pues había de mentir el señor don Quijote, que, aunque quisiera, no ha tenido lugar para componer e imaginar tanto millón de mentiras?

-Yo no creo que mi señor miente - respondió Sancho.

-Si no, ¿qué crees? -le preguntó don Quijote.

-Creo -respondió Sancho- que aquel Merlín, o aquellos encantadores que encantaron toda la chusma que vuestra merced dice que ha visto y comunicado allá abajo, le encajaron en el magín o la memoria toda esa máquina que nos ha contado y todo aquello que por contar le queda. (219) 
Y, en una dialéctica que oscila de lo posible a lo imposible, de lo real a lo fantástico, y a la vez de la verdad a la mentira, de la historia a los encantamientos, don Quijote involucra a Sancho y a sus dotes de encantador, con el encantamiento de Dulcinea. Esto nos hace pensar que don Quijote nunca creyó que la tosca aldeana y sus dos compañeras, que le mostró Sancho, fuesen Dulcinea y sus damas: “Todo eso pudiera ser, Sancho, -replicó don Quijote-, pero no es así, Montesinos [...] me mostró tres labradoras que conocí ser la una, la sin par Dulcinea del Toboso, y las otras dos aquellas mismas labradoras que venían con ella, que hablamos a la salida del Toboso [...]" (220). Sancho queda desconcertado, pues sabía la verdad del fingido encantamiento de la dama y que él había sido el encantador; parece que advierte la importancia del contraste entre los tiempos de fuera y de dentro de la cueva, y resume:

En mala coyuntura y en peor sazón y en aciago día bajó vuestra merced, caro patrón mío, al otro mundo, y en mal punto se encontró con el señor Montesinos, que tal nos le ha vuelto. Bien se estaba vuestra merced acá arriba en su entero juicio, tal cual Dios se le había dado, hablando sentencias y dando consejos a cada paso, y no agora, contando los mayores disparates que pueden imaginarse. (220)

Para Sancho la locura en que estaba situado don Quijote antes de bajar a la cueva, era la forma ordinaria de estar, la normal: alternaban los juicios y consejos en discursos brillantes con algún episodio que había que explicar por la intervención de los encantadores y que era un tributo a la ficción, pero ahora, a la salida de la cueva don Quijote pierde el juicio y dice disparates. El proceso de inversión es total.

Cervantes abre el cap. XXIV con un recurso de intensificación. El motivo de la cueva es tan relevante en la trama de la novela que el "traductor" se sale de su ámbito para dar fe de que en el manuscrito original figura una anotación de Hamete Be- 
nengeli donde repasa las soluciones diversas que el texto había propuesto para este caso:

No me puedo dar a entender, ni me puedo persuadir, que al valeroso don Quijote le pasase puntualmente todo lo que en el antecedente capítulo queda escrito: la razón es que todas las aventuras hasta aquí sucedidas han sido contingibles y verisímiles, pero ésta desta cueva no le hallo entrada alguna para tenerla por verdadera, por ir tan fuera de los términos razonables. Pues pensar yo que don Quijote mintiese, siendo el más verdadero hidalgo y el más noble caballero de sus tiempos, no es posible; que no dijera él una mentira si le asaetearan. Por otra parte, considero que él la contó y la dijo con todas las circunstancias dichas, y que no pudo fabricar en tan breve espacio tan gran número de disparates; y si esta aventura parece apócrifa, yo no tengo la culpa; y así, sin afirmarla por falsa o verdadera, la escribo. Tú, letor, pues eres prudente, juzga lo que te pareciere, que yo no debo ni puedo más; puesto que se tiene por cierto que al tiempo de su fin y muerte dicen que se retrató della, y dijo que él la había inventado, por parecerle que convenía y cuadraba bien con las aventuras que había leído en sus historias. (223)

Textualmente el episodio acaba en tablas: no se aclara si don Quijote mintió conscientemente, o se equivocó en sus sueños, o intentó tomar la respuesta adecuada al encantamiento que Sancho había urdido sobre Dulcinea; no se sabe si don Quijote queda sorprendido por sus historias y por la discordancia temporal dentro y fuera de la cueva, o bien, su historia inventada se encuentra sin preverlo con tal desajuste; la lógica de la perplejidad es fuerte y desconcertante, de modo que el caballero sigue sus aventuras, pero se encamina hacia la cordura y la muerte, y el cambio se inicia en la aventura de la cueva de Montesinos, tan minuciosamente relatada. 


\section{Referencias bibliográficas}

Bobes Naves, María del Carmen (1994), “El tiempo como unidad sintáctica del Quijote," en Cervantes. Estudios en la víspera de su centenario. Kassel, Reichenberger 125-143.

Bobes Naves, María del Carmen (2012), Realidad, Literatura y Conocimiento en la Novela de Cervantes. Arco Libros 126-147.

Cervantes Saavedra, Miguel de (1997), Don Quijote de la Mancha. 2 vol. $2^{\underline{a}}$ ed. Madrid, Castalia.

María del Carmen Bobes Naves

UNIVERSIDAd DE OVIEDO 
